\title{
APONTAMENTOS SOBRE ÉTICA NA PESQUISA: TENSÕES DA EDUCAÇÃO NO ENCONTRO COM A SAÚDE
}

\author{
Notes about research ethics: tensions of education in the encounter \\ with the health
}

\section{Ricardo Burg Ceccim}

Pós-doutor em antropologia

médica, Programa de Pós-

Graduação em Educação e

Programa de Pós-Graduação em

Saúde Coletiva, professor de saúde

coletiva na Universidade Federal do

Rio Grande do Sul.

E-mail: ricardo@ceccim.com.br

\section{Daniele Noal Gai}

Doutoranda em Educação,

Faculdade de Educação e Programa de Pós-Graduação em Educação, professora de educação especial na Universidade Federal do Rio Grande do Sul.

E-mail: daninoal@gmail.com

\section{Resumo}

Esta escritura foi disparada com o seminário avançado sobre Ética na pesquisa, que envolvia questões e proposições para a Educação e para a Saúde Coletiva, realizado no primeiro semestre letivo de 2014, na Universidade Federal do Rio Grande do Sul - uma promoção dos Programas de Pós-Graduação em Educação e em Saúde Coletiva. Trouxemos, neste artigo, apontamentos sobre a vida e os encontros, tomando-os como tarefa ética quando se investiga em ciência e na produção de conhecimento em saúde. Pensamos, aí, uma Ética "da educação" no cuidado em saúde. Sugerimos a potência de permanentemente aprender, durante a pesquisa, porque se pesquisa. Pesquisar é aceitar o imprevisível, é se deixar ser afetado, é a capacidade de suportar o que não para de diferir. Pesquisar exige Ética para com o que pede passagem, com a densidade da vida e com a labilidade das formas. Propomos que "parafernálias do encontro" - e não as tralhas tecnológicas - sejam disparadoras de potência para a afirmação da vida.

Palavras-Chave: Ética em pesquisa; Pesquisaeducação; Pesquisa-saúde; Vida-saúde; Vidaeducação.

\section{Abstract}

This writing was triggered by the advanced seminar on Ethics in research involving issues and propositions for Education and Collective Health. The seminar was held in the first semester of 2014, 
in the Federal University of Rio Grande do Sul, promoted by the programs of Graduate Studies in Education and Collective Health. We brought, in this article, notes on life and encounters, taking them as an ethical task when investigating in science and in knowledge production in health. We think, there, an "education" Ethics in health care. We suggest the potency of learning permanently, during the research, why we research. Researching is accepting the unpredictable; is to letting yourself be affected; it is the ability to endure what does not stop from differ. Researching requires Ethics to what asks for passage, to the density of life and to the lability of the forms. We propose that "paraphernalia of encounter" - and not the technological junk - be the trigger of the potency to the affirmation of life.

Keywords: Research ethics; researcheducation; research-health; life-health; lifeeducation.

\section{Introdução}

O presente documento de escrita reúne argumentos acerca da Ética na pesquisa, envolvendo questões da Educação para com a Saúde. Trazemos para a cena, neste artigo, apontamentos sobre a Vida e os Encontros, tomando-os como tarefa Ética quando se investiga em ciência e na produção de conhecimento. Sugerimos a potência de permanentemente aprender, durante a pesquisa, porque se pesquisa. Pesquisar é aceitar o imprevisível, é a capacidade de suportar o que não para de diferir. Pesquisar exige Ética para com o que pede passagem, com a densidade da vida e com a labilidade das formas. É importante indicar que os apontamentos que se seguem nos foram evocados por um seminário avançado sobre Ética na pesquisa, envolvendo questões e proposições para a Educação e para a Saúde Coletiva, realizado no primeiro semestre letivo de 2014, na Universidade Federal do Rio Grande do Sul, uma promoção dos Programas de Pós-Graduação em Educação e em Saúde Coletiva. No decurso de debates sobre pesquisa, ciência e produção do conhecimento, o tema da Ética nos surgiu com relevo singular às interfaces entre a Educação e a Saúde Coletiva. O pano de fundo era o de uma pergunta: como propor uma Ética na produção de conhecimento do e no contemporâneo? Dito de outra forma: como propor uma Ética em meio à vida e aos encontros? Pergunta que nos temos feito em meio às pesquisas que orientamos na graduação e na pós-graduação em Educação e na Saúde Coletiva, que colhem o humano, a vida ou as redes, na sociedade, em seus movimentos intensivos, abertos, em ato.

Trata-se, no nosso caso, do tema da produção de conhecimento como "estudo-ação" ou "pesquisa-formação", o tema da pesquisa como "pesquisa-ação" ou "pesquisa-intervenção", o tema da ciência como "comunidades ampliadas de pesquisa" ou "comunidades científicas ampliadas" ${ }^{1}$ Nossos esforços de estudo e pesquisa atravessam a tematização de uma Ética da educação (do aprender) instaurada no campo da saúde (do atender), onde se cruzam questões do aprender/ensinar e do atender/tratar, tendo em vista o rigor com que se deve operar dados, informações e conhecimentos sobre alunos, pacientes, professores, usuários de serviços de saúde, etc. Nossos temas envolvem educação em saúde, educação especial, saúde mental coletiva, humanização do cuidado em saúde, educação e promoção da saúde, formação de professores e de profissionais de saúde.

Foram feitas inúmeras propostas de estudo, ao longo do Seminário, que alongavam as intenções de escavação e refinamento sobre o tema da pesquisa científica e as múltiplas formas de produção de conhecimento que envolvem, em maior ou menor grau, práticas científicas, filosóficas ou artísticas. Os plenários foram 
contribuidores, sobretudo as conversações que se deram no debate que acontecia quando estávamos juntos em torno de um texto, um exemplo, um modelo ou um desafio. Parece-nos que olhar por todos os lados é a principal reivindicação do contemporâneo. O contemporâneo nos interessa, sua prospecção de futuros ou a projeção de mundo que nossos atos geram na pesquisa, ciência e produção do conhecimento. Forma e resultados não se dissociam, a forma delineia a vigília e a organização dos resultados. Nova pergunta: o que se inclui e o que se exclui por força dos limites que impomos pela forma e pelo estilo de vigília? Vasculhamos, então, em Seminário, aspectos relacionados às exigências, normativas e falsas proposições no que se refere à Ética nas ciências humanas, na área de humanidades como um todo ou nas chamadas ciências sociais e humanas na saúde.

Tratou-se, em aulas abertas aos mestrandos, doutorandos, professores, pesquisadores e à comunidade interessada, sobre o que é da ordem legal, moral ou processual em ciência. Sugerimos à análise os direitos autorais, o plágio em pesquisa, os trâmites e burocracias na pesquisa universitária, as comissões científicas e suas exigências internas de trabalho, os interesses de agência e grupos de interesse, as comunidades de citação recíproca e as coautorias estratégicas. Conhecer as linhas de pesquisa, a vulnerabilidade de todos e de cada um em meio à investigação científica e à produção do conhecimento não adquire patamar de diálogo, posto que normas antecedentes ou "culturas" científicas cercam as margens de conversação, interação ou composição. Conhecer internamente as intenções dos comitês e comissões na aproximação viva com a Ética ou como relacionam a Ética com a vida não nos parece imediato. Essas questões e perturbações-proposições tornaram-se argumentos para um certo pensar da ação cientifica, intelectual e investigativa.

Por quais agências nossa busca, por quais grupos nossas reivindicações, por qual socius, ambiente e subjetividade nossa produção de mundo do e no conhecimento? Por qual Ética nossa busca, as nossas reivindicações e a nossa ação? Como interlocutores, numa abertura para conversa, inventariamos percursos e autorizamos alguns rumos. Em grupo, num coletivo, num esforço intelectual rigoroso legitimam-se acepções para as coisas que são da ordem dos coletivos, da ordem do humano, da ordem da vida. Na ordem/ ordenamento das pesquisas tudo isso se considera?

Por quais percursos investimos pesquisa? Por quantos paradoxos, uma pesquisa? Pesquisas em meio ao contrassenso, confrontadas na experimentação com o dissenso, com a diferença, são emergências no contemporâneo! Como estabelecer protocolos, preâmbulos, procedimentos de pesquisa frente à multiplicidade ou a pluralidade da Ética? Sob diferentes perspectivas, perante diferentes filiações e diante da multiplicidade dos processos de pesquisar e perceber, certamente não encontramos uma única e mesma ou permanente Ética. Porém, se sabendo do perspectivismo, das inscrições teóricas e da multiplicidade, se assinalam e se exigem responsabilidade, rigor e seriedade com matérias e métodos de saber. A construção dos modos de pensar-sentir-querer por si só indica a Ética em ciência ou das relações, a função ou disfunção da introdução de protocolos e termos de proteção de quem pesquisa e de quem é (ou daquilo que é) pesquisado.

Perante o plural e o impermanente, assim como de forma distante da Verdade, da prova e do controle, quais percursos seguir? O que fazer com sutilezas, delicadezas, invisíveis ou incorporais? Informes somente acessados em meio à vida "no lugar", no 
lugar da alteridade, no lugar do encontro, no lugar em mutação, inclusive do pesquisador quando pesquisa, durante a pesquisa e porque pesquisa.

Como mobilizadores de pensamento e de mudanças, enunciamos a autorização e a legitimação como pontos para nos pensarmos, num processo de aprendizado de si, ou seja, em lugar de um Termo de Consentimento remetido ao outro, a diligência de si, não um proteger-se de risco gerado ao outro, mas um confrontarse com sua autorização e legitimidade aos encontros, à produção da vida, em meio à pesquisa.

Quanto à autorização:

a) autorização da pesquisa - oportuna ao autor;

b) autorização do tema - constructo processual do autor;

c) autorização do campo - intervenção conforme os vínculos possíveis ao autor;

d) autorização das análises - com expectativa de compromisso autoral;

e) autorização da publicação - com expectativa de atualização da pesquisa por redes de conversação.

Quanto à legitimação:

a) legitimação da pesquisa - oportuna a um programa de pesquisa e seus pesquisadores;

b) legitimação do tema - constructo processual de uma linha de pesquisa;

c) legitimação do campo intervenção conforme as demandas da contemporaneidade da pesquisa;

d) legitimação das análises - com expectativa de convocação social entre os interessados;

e) legitimação da publicação - com expectativa de interação no socius, no ambiente e na subjetividade em causa.

Poderíamos dizer de outro modo tudo isso, já que em diferentes perspectivas da ciência e da vida é possível uma Ética da educação (do aprendizado), como uma Ética da atenção (do cuidado). No que se refere à educação e à saúde, na deficiência, no transtorno mental ou na convalescença, pode-se perguntar: quais as matrizes de experiência ou para a interferência na deficiência, na doença, na ineficiência, no adoecimento, na invisibilidade/ inviabilidade, no silenciamento/supressões?

Como, na deficiência, no sofrimento, na doença e supostas doenças, tornar-se "sujeito de si"? ?,3 Consigo mesmo, por si mesmo e para si mesmo? Compondo-se d'outros? Com-vivendo? Acompanhado do mundo, dos seus cacarecos e de outras coisas? Comparado aos processos de desenvolvimento de intensidades? Avaliado sob a multiplicidade da potência e do devir? Avaliado sob as medidas dos encontros alegres? Avaliado sob as medidas do que está à flor da pele, do que se faz com simplicidade, enfrentamentos, risco e riso? Como construir-se em meio à vida? Experimentando a deficiência, o transtorno ou a doença como potência para a vida?

Como inventar espaços escolares ou de saúde em que o cuidado, o afeto e a vida sejam aprendidos em meio à experiência do que se transforma em meio à vida? Como abrir as possibilidades de vida-aluno-comdeficiência, vida-pessoa-em-sofrimento ou vida-"paciente"-convivendo-com-vírus ou isso ou aquilo na contemporaneidade? Como desassujeitar naturalizações de outros tempos e construir práticas de convívio com o que se é, com o que um aluno é, com o que um usuário de serviço de saúde é, com o que ele traz nos bolsos, com o que seus olhos caçam do entorno ou seus corpos compõem em mosaicos e bricolagens, com o histórico de vida que ele porta?

Como construir práticas de vida no dissenso, na multiplicidade, na efervescência do sem sentido? Como construir práticas de vida paradoxais, inelegíveis, não classificáveis, ilegíveis, de difícil tradução, descrentes de preconceitos e com puro 
rigor no que se concebe como encontro? Como pensarmos-produzirmos corposrabo-de-lagartixa plenos em plasticidade? Como produzir um corpo sempre prestes a epifanizar-se? ? $^{4,5}$

\section{Pensar possibilidades}

Pensar possibilidades de moldar, remodelar, aliterar, inverter e fazer verter em pesquisa requer questões de pensamento. Reivindica-se práticas de contemporâneo, exige-se uma ética viva e atenta, em devir, em ato. De modo que o que se contrata em meio à alteridade valha naquilo que se faz ali, em ato. De modo que piscar o olho e fazer combinações valha tanto quanto contrato, pois que naquilo que se agencia há acontecimento. Naquilo que se acha, nos achadouros de escola e serviços de saúde, por exemplo, sob combinação daqueles que procuram algo, juntos, perfaz-se uma Ética.

Termos conversado sobre

uma possível Ética contemporânea da alteridade, nos trouxe questões desdobradas do contemporâneo: Ética da alteridade, Ética do viver junto, Ética do compartilhamento, Ética da conectividade, Ética do deslocamento, Ética viva, Ética da amorosidade, Ética do brincar, Ética do riso. Éticas caçadas pelos protocolos de pesquisa e termos de consentimento livre e esclarecido? Esclarecimento iluminista ou esclarecimento em desmanchamento e recomposição singular e viva de corpos de afeto? O que fazer com a ética-atenção que espraia-se como ética do viver junto, ética das intensidades?

Interessa provocar tal suscitação em educação ou em saúde? Especialmente em educação especial, em saúde mental ou em saúde coletiva, onde se quer transpassar a lógica da habilitação e reabilitação, do diagnóstico e da cura, onde se quer a possibilidade do ritmo da vida, a vida que possa se dar no comunitário, sob coletivos e em meio ao socius, ambiente e subjetividade? Conquanto aquele com existência fragilizada, com corpo adoecido, queira um pouco de ar para não sufocar ${ }^{6}$, um pouco de ar puro ${ }^{7}$, outro. A quem se dedica um cuidado privativo, se requer a proximidade com o humano, não com o prevenível ou, exatamente, com o não prevenível. Aquele que recebe o cuidado privativo quer aquilo que é da ordem do humano, quer viver junto (habitar um tempo com outrosi), mesmo que a dois em tropeços, quer a intensidade, o desafio.

Nietzsche, ao reivindicar "ar puro!, ar puro!", dirá mais: "em todo caso, (...) longe dos perniciosos miasmas da putrefação interior (...)". Esse pensamento sem idealismo levaria ao conhecimento. Esse conhecer, ele chamou de "conhecimento trágico" 8 : uma nova forma de conhecimento - discrepante da racionalidade clássica - e que resulta de olhar o "inesclarecível", isto é, de ver o que está fora da rede de impenetrabilidade tecida pelo saber lógicoexplicativo e de entrar em contato com a necessidade de reconfigurar o saber em uma nova estética da existência. Está mais próximo da arte (metafísica artística) que daquilo que chamamos ciência (metafísica racional).

É certo que não existe só uma prática do ensinar, e tampouco só uma prática do cuidar. Estar preparado para trabalhar com uma vida fragilizada em sua existência é poder colocar-se no lugar de quem aprende, de quem é atendido, é poder lançar o olhar para além do que está posto, tocar o incorporal, ver o invisível, sentir o impalpável. É implicar-se, é querer e fazer parte do processo, é lembrar-se das redes transetoriais, é encontrar-se com aqueles a serem cuidados com uma Ética, ${ }^{9}$ aumentando sua potência de querer e de

\footnotetext{
Habitar um tempo com outros se refere ao compartilhar compreensões, a vida. Isso pode ocorrer pelo contato com a literatura, o teatro, a dança, por exemplo. Então, não se trata de uma noção romântica do gregário, mas da produção humana em meio à vida
} 
agir. Propor-se ao encontro. Encontro que só pode ser único.

Diante do encontro, quantas antecipações posso ofertar? Quantas antecipações posso consentir? Quantas emoções/afecções posso prevenir? Em que medida antecipações, consentimentos e prevenções impedem ou favorecem o encontro ético? Há necessidade da ética viva, processual in actu? Pensar possíveis para um encontro que seja específico, ativo, efetivo, pontual, um movimento, uma aproximação, um deslocamento, uma atenção, uma escuta, um sentido, uma voz: antecipações, consentimentos, prevenções são possíveis? Fazem sentido?

O encontro se faz na potência do estar junto, na potência das intensidades, na potência das disrupturas a que se busca ou precisa. $O$ encontro se faz na atração de sensibilidades. O encontro pode ser a Ética? $O$ encontro pode ser a condução? Encontro como atenção? Encontro singular? Encontro como aprendizado? Encontro caseiro? Encontro morada? Encontro estada? Encontro residente? Encontro que reside? Encontro que mora nalgum lugar?

Há necessidade de um "polo cognitivo de singularização, de particularização da pesquisa"10 (no outro polo estaria a racionalidade da ciência) para afirmar a criação processual e, em lugar do paradigma da Verdade, estaria uma modelização localizada, encarnada em um corpo social cujo destino está em causa. Os enunciados de pesquisa, numa mudança de atitude do pesquisador em relação a seus interlocutores, podem ser chamados de agenciamento coletivo de enunciação. "A elaboração cognitiva, neste caso, é inseparável do engajamento humano e da escolha de valores em que implica".

Propõe-se que "parafernálias do encontro", não as tralhas tecnológicas, sejam disparadores de potência para a afirmação da vida. O encontro, como a produção em ato do cuidado em saúde, "é um momento intensamente intercessor". Encontro onde, "de um jeito ou de outro, dele esperam seus agentes a mesma coisa: que seja eficaz para resolver ou aplacar sofrimentos tidos como problemas de saúde"11. Pode-se dizer do aprender em educação a mesma coisa. Encontro desde o qual esperam seus agentes o aprendizado: de si, do mundo, dos entornos. Ou a atenção: para si, para suas inserções/inscrições, para com os possíveis e a recuperação da potência. Letramento da vida que se sucede, acontece em nós, conosco, por nossos atos de mundo.

Uma das competências necessárias do pesquisador é a de estar atento à realidade, mas realidades são moventes e reagem à presença do pesquisador. Como estar atento (em vigília de pesquisa) e "negociar" com a realidade, acolhendo-a, não a rechaçando em nada? A negociação é entendida como um diálogo ou "saldo" da rede de conversações entre os referenciais técnicos, experiências vividas, definições e distinções de necessidades de saúde, necessidades do aprender (necessidades do saber em saúde ou educação). Defendese a entredisciplinaridade para que se reconfigurem as relações em equipe permanentemente ante a complexidade do enfrentamento do mundo real das necessidades em saúde disputando serem reconhecidas e cuidadas. A entredisciplinaridade, entendida como forma de compreender o trabalho multiprofissional e interdisciplinar, tem valor na educação e na saúde. Ceccim fala de "um lugar de sensibilidade e equilíbrio metaestável"12. Pode-se dizer de uma prática, um estado-ação onde emerge o mestiço, o híbrido, o nômade; em que todos os potenciais seguem se atualizando e o equilíbrio não pode ser outro que não a transformação permanente. 


\section{Conclusão}

As anotações neste texto trazem nuances de uma educação e uma atenção que podem ser eficazes desde que abertas à alteridade. Cuidado querençoso. Ensino querençoso. Cuidado amoroso, dedicado ao frágil da saúde, como presente na convalescença, no transtorno, na deficiência. Alteridade/encontro, enlace in actu. Enlace como zona de experimentação, zona de singularização.

Desejosas são as zonas de experimentação entre intuição, cuidado, saúde e educação. $\mathrm{Na}$ perspectiva Deleuzeana, desejar será sempre um ato construtivista. Diz que "não há desejo que não corra para um agenciamento". Desejo, dirá, "é construtivismo". Ainda: "é construir um agenciamento, construir uma região". Desejar é "realmente agenciar", pois que "o desejo é construtivismo"13. Quem e como regula esta Ética. Trabalha-se, nesta noção de pesquisa, não com o que junta, mas com o que separa juntando: operadoresconectores-disjuntores. São proposições disjuntivas e compartilháveis, tal o contemporâneo que se vive! Habitar um mesmo tempo, habitar uma conversação: eis aí a Ética do encontro. Só descoberto nesta hora e somente porque aí, sob um encontro ético.

Bem, falar de uma produção de conhecimento que é "girar por cima do assunto (viver-junto)"14, de uma pesquisa que segue em vias de se fazer. Diz acreditar que, para haver de fato uma relação de ensino que funcione, "é preciso que aquele que fala saiba só um pouco mais do que aquele que escuta (às vezes, mesmo, sobre certos pontos, menos: são vais-evens)". Assim, mesmo a construção do conhecimento é pesquisa, não aula ${ }^{14}$. A pesquisa: científica ou construção do conhecimento? A ciência: protocolar ou margens à construção do conhecimento

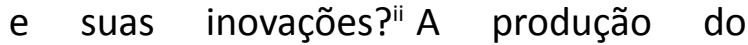
conhecimento: repetição, recognição ou construcionismo, conversação de saberes e suas disrupturas?

Afirma a transgressão, marcar a decomposição e a desocupação dos territórios identitários, abrindo-os à raridade e ao inusitado. Como compor uma pesquisa do quase nada? Como compor uma pesquisa com a junção de restos de corpos debilitados, enlouquecidos, frágeis, vitais? Desde a filosofia, a arte, a saúde, a ciência, as pedagogias do corpo e da saúde? Como se fazer entender com intercessores surtados, epilépticos, sufocados, suicidas? Como compor um Corpo sem Órgãos ${ }^{15}$ e fazê-lo produzir sentidos em uma escavação de pesquisa? $\mathrm{O}$ que se pode com um corpo nada de corpo? Com um vazio que se preenche por dentro? Como afectar sem avessos? Como, aos moldes de Lygia Clark, promover abertura na subjetividade para um além do humano: o autêntico bicho (o vivo)? Como fazer outras dobras toda vez que um novo feixe de sensações assim existir/exigir? Como fazer outras perguntas sempre que o contemporâneo nos afrontar? Pesquisar! Pois que vivemos, fazemos vida. A ciência humana é feita dessa matéria, enfim.

Trouxemos apontamentos, apontamentos sobre a vida e os encontros, tomando-os como tarefa ética quando se investiga em ciência e produção de conhecimento em saúde. Pensamos aí uma Ética "da educação" na atenção em saúde: permanentemente aprender quando em pesquisa, durante a pesquisa, porque se pesquisa. Pesquisa não pode ser antecipação, se for educação, se for aprender, se for ensinar e aprender.

\footnotetext{
ii Construção e produção do conhecimento: práticas diversas. Enquanto a construção é o aprendizado do conhecimento acumulado pela humanidade, um fazer de escola, a produção é ensaístico-investigativa, um fazer da comunidade científica. Construção e produção, entretanto, são pesquisa. O que fazer com a não ou difícil distinção. Por ventura desejá-la?
} 
Sabemos de saúde e de educação por seus lugares de exigência pela radical Ética da vida: educação especial, saúde mental, saúde coletiva, formação de professores e formação de profissionais do cuidado em saúde. Pesquisar é aprender e adquirir um poder de ser afetado, é a capacidade de suportar o que não para de diferir, aceitar o imprevisível. Pesquisar exige Ética para com o que pede passagem, com a densidade da vida e a labilidade das formas.

\section{Referências}

${ }^{1}$ Ceccim RB, Müller GS, Maia LP, Cataluña RV. A proposta de pesquisa-formação em saúde: construção do método de Círculos em Redes. RECIIS - R. Eletr. de Com. Inf. Inov. Saúde, 2013 dez;7(4).

${ }^{2}$ Foucault M. A hermenêutica do sujeito: curso dado no Collège de France (1981-1982). 3. ed. São Paulo: Martins Fontes; 2010.

${ }^{3}$ Foucault M. A coragem da verdade: o governo de si e dos outros II, Curso no Collège de France (1982-1983). São Paulo: Martins Fontes; 2011.

${ }^{4}$ Noal Gai D, Ferraz W (Org.). Parafernálias: diferenças, artes, educação. Porto Alegre: INDEPIn; 2012.

${ }^{5}$ Noal Gai D, Kersting AB, Martins I, Soares O, Ferraz W. Notas do idiotismo: Arthur Bispo do Rosário e Manoel de Barros. In: Gonçalves C. (Org). Caderno de notas 5: oficinas de escrileituras - arte, educação e filosofia. Oficinas produzidas em 2011. Pelotas: Editora Universitária/UFPel; 2013:65-67.

${ }^{6}$ Woolf VV Woolf: contos completos. São Paulo: Cosac Naïfy; 2005.

${ }^{7}$ Nietzsche FW. La genealogia de la moral: un escrito polémico. Madrid: Alianza Editorial; 1995.

${ }^{8}$ Nietzsche FW. O nascimento da tragédia ou Helenismo e pessimismo. São Paulo: Companhia das Letras; 1992.

${ }^{9}$ Spinoza B. Ética. Belo Horizonte: Autêntica; 2009.

${ }^{10}$ Guattari, F. Fundamentos ético-políticos da interdisciplinaridade. Revista Tempo Brasileiro, 1992;(108): 19-25.

${ }^{11}$ Ceccim RBC. O que é saúde? O que é doença? In: Meyer DE E (Org.). Saúde e sexualidade na escola. Porto Alegre: Mediação; 2012:37-50.

12 Ceccim RBC. Equipe de saúde: a perspectiva entredisciplinar na produção dos atos terapêuticos. In: Pinheiro R Mattos RA. Cuidado: as fronteiras da integralidade. Rio de Janeiro: Abrasco: 2006:259-278.

${ }^{13}$ Deleuze G. O abecedário de Gilles Deleuze. Transcrição de entrevista realizada por Claire Parnet, direção de Pierre-André Boutang, 1988-1989. Disponível em: <www.oestrangeiro.net/ index2.php?option=com_content\&do_pdf=1\&id=67>. Acessado em 17/08/2014.

${ }^{14}$ Barthes R. Como viver junto: simulações romanescas de alguns espaços cotidianos; cursos e seminários no Collège de France, 1976-1977. São Paulo: Martins Fontes; 2003.

${ }^{15}$ Deleuze G. Francis Bacon: lógica da sensação. Rio de Janeiro: Jorge Zahar; 2007. 